\title{
Electrical Conductivity of Waxes as Model Systems for Polyethylene: Role of Water
}

\author{
Ian Hosier, Alun Vaughan \\ Electronics and Electrical Engineering Group, Building 1, University of Southampton, Highfield, Southampton, \\ SO17 1BJ, UK
}

\section{Nick Quirke}

Department of Chemistry, Imperial College, 301G Molecular Sciences Research Hub, White City Campus, 80 Wood Lane, London, W12 OBZ, UK

Correspondence to: Ian Hosier, ilh@soton.ac.uk, Nick Quirke, n.quirke@ic.ac.uk

\begin{abstract}
Novel experimental and theoretical studies of the electrical conductivity of high-purity dodecane, paraffin wax and low density polyethylene are reported herein. The role of the charge density, water content and phase changes in determining conductivity as the temperature increases from $25^{\circ} \mathrm{C}$ to $65^{\circ} \mathrm{C}$, a temperature range relevant to applications of insulating materials, is determined. Low levels of absorbed water determine the measured conductivity for $\mathrm{T}<50{ }^{\circ} \mathrm{C}$ and this can be explained by taking account of the charge carriers produced by the auto-ionisation of water. In comparison to commercial polyethylene and lubricating oils, the temperature dependence of the conductivity of dry n-dodecane is anomalously high.
\end{abstract}

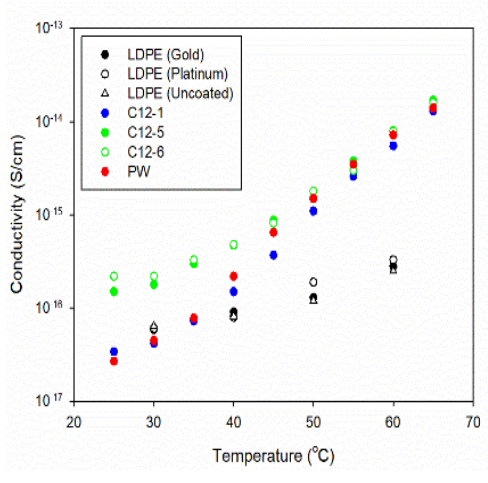

\section{INTRODUCTION}

Electron trapping processes have been linked to dielectric breakdown in polymeric insulation ${ }^{1}$ which is significant for high-voltage cables used for power transmission. Around $9 \%$ of generated electricity is lost through transmission and distribution ${ }^{2}$, amounting to an estimated financial loss of 3 trillion U.S. dollars a year worldwide ${ }^{3}$. Furthermore, with the continuing uptake of renewable energy sources comes the need for a new generation of ultrahigh voltage long distance direct-current (DC) transmission cables. This in turn calls for ultrapure insulation materials with extremely low electrical conductivity.

While much progress has been made in our understanding of electron trapping and charge transport in dielectric materials such as polyethylene, comparison with experiment remains problematic due to the ubiquitous nature of water in the environment, the presence of various chemical defects and the impurities and additives inherently present in all practical polyethylene systems. Many theoretical studies have been undertaken in order to understand charge transport in non-polar insulating analogues of polyethylene. Early studies considered conductivity through simple homogenous fluids composed of small n-alkanes such as methane and ethane. ${ }^{4}$ In methane, an excess electron was found to be in an extended state throughout the whole fluid density range. In ethane and higher alkanes, by contrast, it is found that an excess electron can be localised with cavity formation occurring at a fluid density where, experimentally, the electron is found to have a very low mobility. In solids, rather than create 
a cavity, an excess electron may be trapped by pre-existing nanovoids. In previous work we have used a pseudopotential approach to predict the density of states for excess electrons in bulk polyethylene (PE), including the mobility edge between delocalised states and those states representing electrons localised (trapped) at nanovoids in bulk polyethylene with radii of up to $0.4 \mathrm{~nm}$ with energies $\leq-0.4 \mathrm{eV} .^{5}$ The nanovoids arise from disorder in the molecular configurations of the PE chains. A key result is the low mobility of charge carriers in the ordered lamellar phases as opposed to the amorphous regions, which implies that the bulk of the electrical conductivity takes place within the amorphous regions. In the presence of chemical defects, free surfaces and impurities, much deeper trapping energies are found, which will have a profound effect on conductivity if present in sufficient quantities. ${ }^{3,6,7}$ Theoretical studies of silica/polyethylene nanocomposites confirm the presence of surface states in polyethylene but also revealed very deep traps in silica nanoparticles. ${ }^{8}$ Introducing water to these models demonstrates its all important role, both in determining the surface hydroxylation and hence the surface trapping state of the silica interface, but even more significantly, if present as a water film, in creating very mobile hydrated excess electrons in the adsorbed water film. Clearly, water can play an important role in modifying charge transport as is seen in experimental measurements of conductivity in silica/polyethylene nanocomposites with variable water content. $^{9}$

Elucidating the precise nature of conduction in non-polar materials would be facilitated by working with samples which can be prepared in a chemically pure state and whose morphology is easily controlled. Wax is an obvious choice and indeed the conductivity of paraffin wax and oil has been studied since $1932 .{ }^{10-12}$ However, the measurement of conductivity at very low values presents its own unique challenges; the preparation of chemically pure samples is difficult and existing data sets are not adequate for detailed comparisons with molecular simulation/ab initio models. Here, we are particularly interested in obtaining accurate data on the role of moisture in controlling conductivity in pure non-polar systems, as it will be present in most insulating materials and may well play an important role in determining conductivity. For instance, it is known to have a determining influence on the electrical conductivity of barrier oils in equipment used in high voltage direct current applications (HVDC). ${ }^{13}$

In order to perform reliable measurements of very low values of electrical conductivity the literature provides important guidance. Theoretical models predict that above $\sim 10 \mathrm{kV} / \mathrm{mm}$ the measured conductivity is strongly influenced by the applied field and this is borne out by experiment. ${ }^{7}$ For instance, electrical conductivity is reported to be independent of applied field in the range $2-15 \mathrm{kV} / \mathrm{mm}^{14}$ whilst, elsewhere, ${ }^{15}$ it was reported that the electrical conductivity is strongly dependent on applied field above $20 \mathrm{kV} / \mathrm{mm}$. In the work reported here, we sought to work in a regime where the measurements are not unduly influenced by the applied electric field, which suggests that: (a), a constant applied field be used; (b) all work is performed with fields $<20 \mathrm{kV} / \mathrm{mm}$. However, another complication is evident in working under constant field conditions; that is, the current is observed to fall over a period of hours. ${ }^{15}$, 16. Therefore, sufficient measurement time must be allowed if a reliable steady state current is to be assured.

Additional complications are posed by the influences of both water ${ }^{9,13}$ and impurities ${ }^{17}$ and so these factors must either be eliminated or controlled. Additionally, temperature can influence electrical conductivity ${ }^{15,18}$ and, therefore, this variable also needs to be properly controlled. Here, we have sought to overcome many of these difficulties by employing two high-purity alkane based systems whose chemical composition is well defined. In addition, by using conditioning (i.e. the exposure of samples to varying atmospheric conditions) we have sought to control our samples' water content. As a further verification of the experimental design and methodology, the conductivity behaviour of a commercial low-density polyethylene 
(LDPE) film was also assessed. Different electrode materials were applied to this sample to check their influence on the measured data.

\section{Experimental}

\section{Materials}

Anhydrous n-dodecane $\left(\mathrm{C}_{12} \mathrm{H}_{26}\right)$ and a high purity paraffin wax, were both supplied by Sigma Aldrich. In the following text the following notation is used for the sake of brevity; C12 is used to refer to the material n-dodecane, C12-x refers to specific samples of n-dodecane, which have been subjected to different conditioning regimes and PW is used to refer to the as supplied paraffin wax - the effect of sample conditioning is not discussed here in connection with this system and, therefore, no qualification is required. In addition, low density polyethylene film, $0.2 \mathrm{~mm}$ in thickness, supplied by Goodfellows, was used as supplied and this is subsequently referred to as LDPE.

\section{Physical characterisation}

Gas chromatography mass spectroscopy (GC-MS) was carried out using a Thermo Trace 2000 GC-MS equipped with a RTX-5 MS column. Positive ion electron detection was carried out using a temperature profile; injection at $240{ }^{\circ} \mathrm{C}$, the column was then heated at $20{ }^{\circ} \mathrm{C} / \mathrm{min}$ from 40 to $320^{\circ} \mathrm{C}$ and then held until the end of elution. Differential scanning calorimetry of 10 mg samples was carried out using a Perkin Elmer DSC-7 calibrated with high purity indium. Water contents were measured on $1 \mathrm{ml}$ samples using a GR Scientific Aquamax KF titrator, three independent samples were run to provide an average value.

\section{Electrical conductivity measurements}

The sample cell shown in Figure 1 was used to determine the electrical conductivity of both $\mathrm{C} 12-\mathrm{x}$ and PW. It was constructed by etching copper clad glass fibre board and was designed to permit easy disassembly for cleaning as well as to minimise leakage currents. Figure 1a shows the electrode configuration; one side provides a measuring electrode with a surrounding guard electrode, whilst the other half is used for the application of a high voltage. This arrangement was held together by nylon bolts, nylon washers were used to maintain a spacing of $1 \mathrm{~mm}$ and the whole was then mounted inside a $100 \mathrm{ml}$ glass beaker (Figure 1b). To fill the test cell, the sample (C12 or PW) was poured into the beaker as a liquid and then briefly degassed (100 mbar for $10 \mathrm{~min}$ ) to remove air bubbles: it was found that if this procedure was not followed, then partial discharge activity within the specimen caused unstable current readings. Whilst filling with $\mathrm{C} 12$ could be done at room temperature, $\mathrm{PW}$ had to be heated to $70{ }^{\circ} \mathrm{C}$ to melt; subsequent cooling to room temperature was therefore performed by removing the entire test cell assembly from the oven and cooling in ambient air over $\sim 1 \mathrm{~h}$. PW was then ready for testing whilst C12 underwent an additional conditioning step at room temperature to vary its water content by either vacuum treatment, desiccation or exposure to ambient air. 


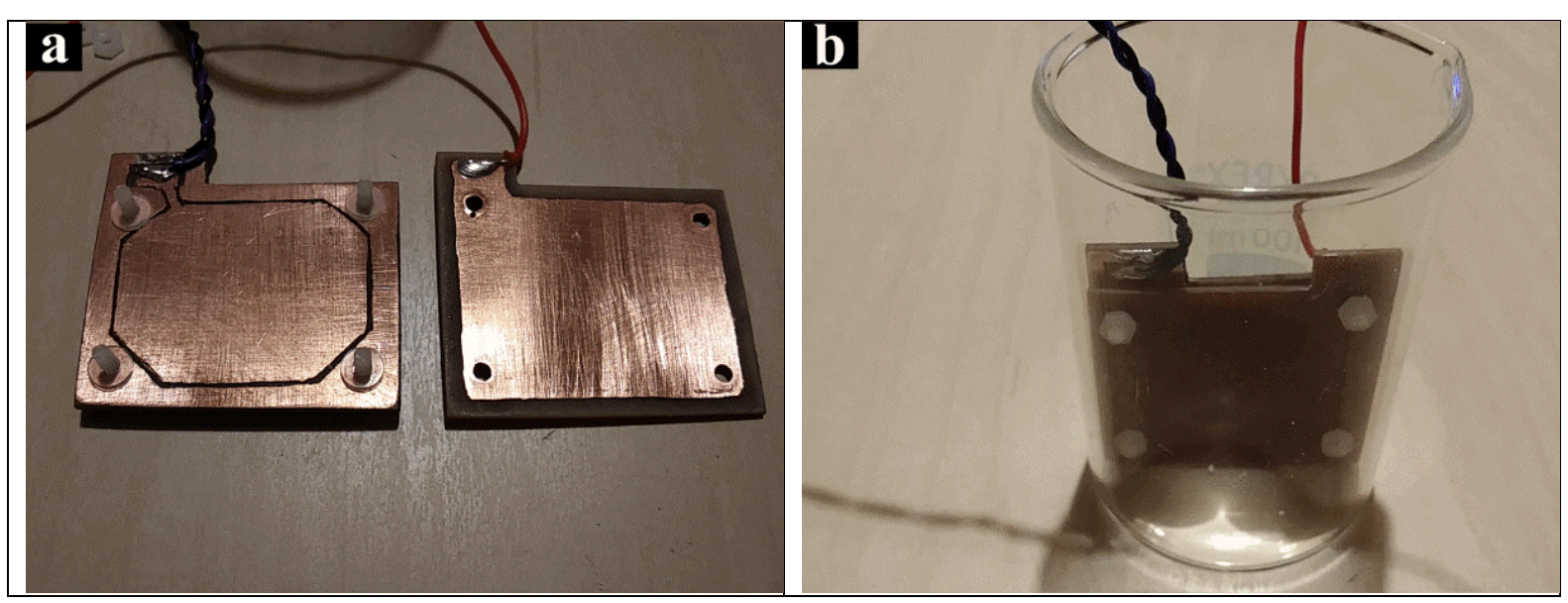

FIGURE 1. Test cell (a) disassembled showing electrode configuration, (b) assembled into glass beaker ready for filling with sample.

To prepare analogous samples of LDPE for electrical characterisation, the as-supplied film was either left uncoated or sputter coated with gold or platinum electrodes (20 $\mathrm{mm}$ in diameter). The samples were then inserted into a test cell composed of spring loaded (100 gf) opposing $20 \mathrm{~mm}$ gold plated brass electrodes and an additional sputtered-on guard ring electrode was used to reduce the influence of surface currents.

Once the test cell was prepared and conditioning undertaken (C12 only), the electrical conductivity of the sample was determined. Automated testing equipment was constructed in house, comprising a Keithley 486 picoammeter and a Spellman SL20 high voltage supply, each of which was computer controlled by National Instruments interface cards. Software, written in Labview, allowed the process of data collection to be automated. The test cell was enclosed within a vacuum oven which permitted the control of both temperature and atmosphere.

A number of preliminary tests were performed to ascertain the effects of applied field and, for as supplied C12 and PW, over the voltage range of $0.5-4 \mathrm{kV}$ (maximum voltage due to the ratings of the high vacuum connectors) the measured conductivity was not observed to vary significantly with applied field $(0.5-4 \mathrm{kV} / \mathrm{mm})$, in line with published reports 14,15 . Application of the same field range to LDPE necessitated applied voltages between 100 and $800 \mathrm{~V}$, which were too low to ensure measurable currents. Accordingly the same range of voltages was applied to these samples (equating to fields of $2.5-20 \mathrm{kV} / \mathrm{mm}$ ) and no significant variation of conductivity with applied field was noted. For consistency and to ensure the field applied to LDPE was not excessive ${ }^{7,14}$, all tests were performed at $2 \mathrm{kV}$, resulting in applied fields of $2 \mathrm{kV} / \mathrm{mm}$ on C12-x and PW and $10 \mathrm{kV} / \mathrm{mm}$ on LDPE. The final testing protocol was to test at a fixed field for 30 min (1 measurement every $10 \mathrm{~s}$ ) using a series of increasing temperatures between $25^{\circ} \mathrm{C}$ and $65^{\circ} \mathrm{C}$ in steps of $5^{\circ} \mathrm{C}$.

\section{RESULTS}

\section{GC-MS}

Figure 2 shows a typical GC-MS trace obtained from PW. The material is clearly polydisperse and the relevant molecule associated with each peak was determined through comparison of their fragmentation patterns to standard libraries. The relative abundances were determined by integration but, due to the uncertainties introduced through estimation of a suitable baseline, the values are calculated to an accuracy of $0.1 \%$ (Table 1 ). PW is composed of 18 distinct homologues ranging from $\mathrm{C}_{20} \mathrm{H}_{42}$ to $\mathrm{C}_{37} \mathrm{H}_{76}$ with a maximum abundance of $\mathrm{C}_{27} \mathrm{H}_{56}$. The other peaks indicated by the software did not have meaningful fragmentation patterns and therefore arise due to background noise; typically, this had a level of $0.1 \%$ relative 
to the maximum relative abundance of $100 \%$ shown in Figure 2 . In terms of the values in Table 1 (where the sum total of all fractions adds up to $100 \mathrm{wt}$. \%) this implies a minimum detectable impurity concentration of $\sim 0.02$ wt. \% or 200 PPM. In contrast, a commercial polyethylene contains antioxidants at typical concentrations of $0.05-1 \mathrm{wt} . \%{ }^{19}$ and other additives, such as flame retardants, may be present in even greater proportions. ${ }^{20}$ Therefore, compared to commercial polyethylene, $\mathrm{PW}$ is a very clean system indeed.

As supplied C12 (see inset Figure 2) presents a single peak with a retention time of 10.22 min and a comparison of its fragmentation pattern to standard libraries confirms that it is $\mathrm{C}_{12} \mathrm{H}_{26}$ (n-dodecane), as expected. No other peaks were evident, so we can again conclude that C12 is free from impurities, at least to our detection limit (0.02\% or 200 PPM), making it, again, a very clean model system.

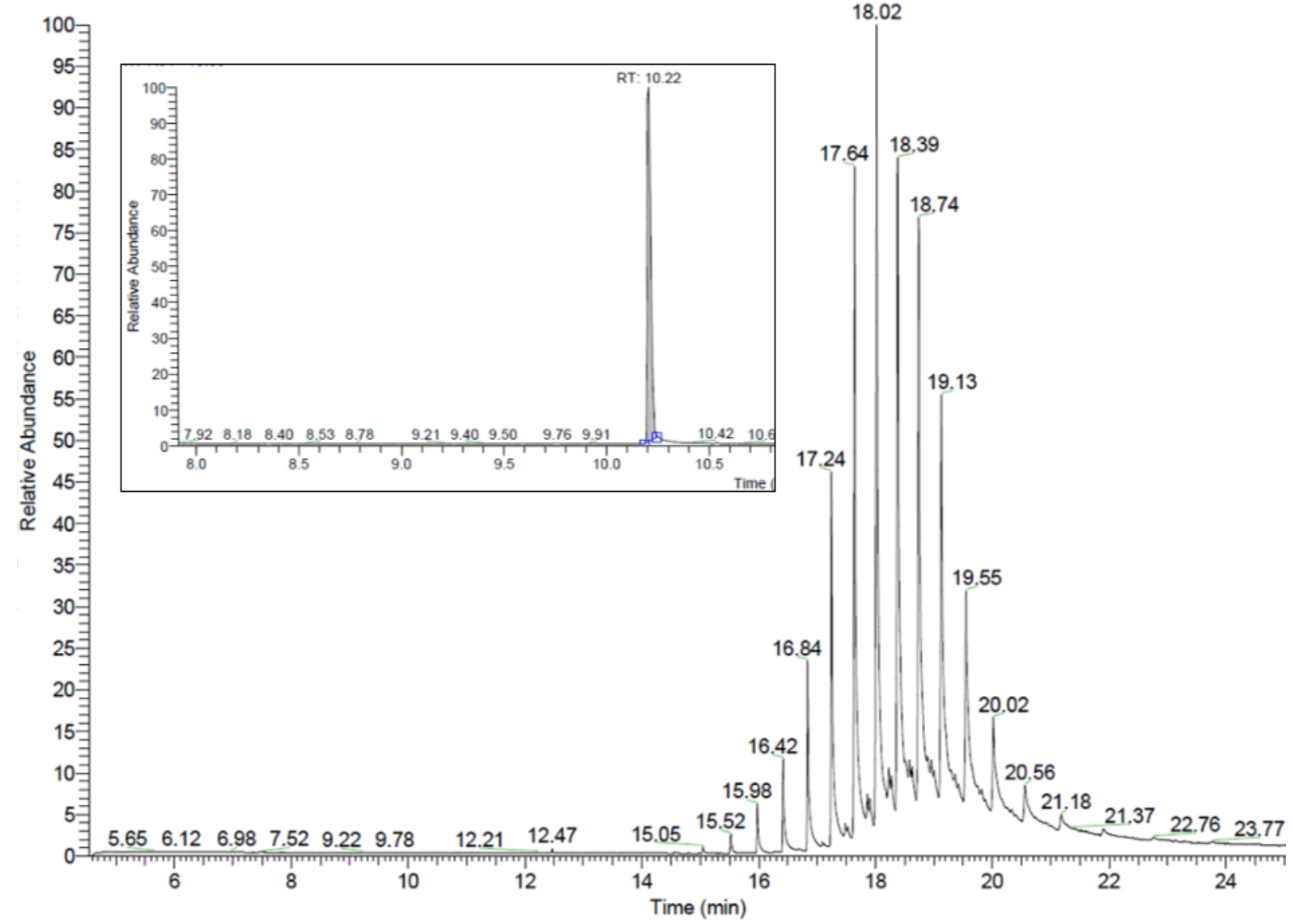

FIGURE 2. GC-MS elution traces from PW and inset C12.

TABLE 1. Relative abundances of the various homologues present in PW

\begin{tabular}{|l|l|l|l|l|l|}
\hline Compound & $\begin{array}{l}\text { Retention } \\
\text { time (min) }\end{array}$ & $\begin{array}{l}\text { Abundance } \\
(\%)\end{array}$ & Compound & $\begin{array}{l}\text { Retention } \\
\text { time (min) }\end{array}$ & $\begin{array}{l}\text { Abundance } \\
(\%)\end{array}$ \\
\hline $\mathrm{C}_{20} \mathrm{H}_{42}$ & 15.05 & 0.2 & $\mathrm{C}_{29} \mathrm{H}_{50}$ & 18.74 & 13.6 \\
\hline $\mathrm{C}_{21} \mathrm{H}_{44}$ & 15.52 & 0.5 & $\mathrm{C}_{30} \mathrm{H}_{52}$ & 19.13 & 9.4 \\
\hline $\mathrm{C}_{22} \mathrm{H}_{46}$ & 15.98 & 1.2 & $\mathrm{C}_{31} \mathrm{H}_{64}$ & 19.55 & 4.9 \\
\hline $\mathrm{C}_{23} \mathrm{H}_{48}$ & 16.42 & 2.3 & $\mathrm{C}_{32} \mathrm{H}_{66}$ & 20.02 & 2.1 \\
\hline $\mathrm{C}_{24} \mathrm{H}_{50}$ & 16.84 & 4.5 & $\mathrm{C}_{33} \mathrm{H}_{68}$ & 20.56 & 1.0 \\
\hline $\mathrm{C}_{25} \mathrm{H}_{52}$ & 17.24 & 9.0 & $\mathrm{C}_{34} \mathrm{H}_{70}$ & 21.18 & 0.3 \\
\hline $\mathrm{C}_{26} \mathrm{H}_{54}$ & 17.64 & 16.3 & $\mathrm{C}_{35} \mathrm{H}_{72}$ & 21.37 & 0.2 \\
\hline $\mathrm{C}_{27} \mathrm{H}_{56}$ & 18.02 & 19.3 & $\mathrm{C}_{36} \mathrm{H}_{74}$ & 22.76 & 0.1 \\
\hline $\mathrm{C}_{28} \mathrm{H}_{58}$ & 18.39 & 15.1 & $\mathrm{C}_{37} \mathrm{H}_{76}$ & 23.77 & $<0.1$ \\
\hline
\end{tabular}




\section{Differential scanning calorimetry}

C12 is a liquid at room temperature while PW is a solid; to characterise the thermal behaviour of the latter, it was first cooled from the melt $\left(65^{\circ} \mathrm{C}\right)$ at various rates in the DSC. The resulting exotherms (Figure 3a) are consistent and indicate that the onset of crystallisation occurs at $58.0 \pm 0.5{ }^{\circ} \mathrm{C}$. Some effects of thermal lag are evident, particularly at the highest cooling rate of $10 \mathrm{~K} / \mathrm{min}$. Subsequent melting scans were then performed at a fixed scan rate of $1{ }^{\circ} \mathrm{C} / \mathrm{min}$, chosen to ensure accuracy in determining the melting temperature. ${ }^{21}$

Monodisperse n-alkanes shorter than $\mathrm{C}_{216} \mathrm{H}_{434}$ always crystallise in the chain extended form, where the crystal thickness is fixed by the molecular chain length rather than by the crystallisation conditions ${ }^{21}$. However, the PW system used here contains a range of different molecular lengths (see Table 1) and while, thermodynamically, the most stable state of the system would correspond to an array of chain extended crystals that conforms to the composition defined above, on kinetic grounds, this is not favoured. Rather, as the temperature falls, the longest molecules initially begin to crystallise into the chain extended form; as the temperature drops further, shorter molecules crystallise both into separate crystals and onto the existing crystal growth surfaces. Comparable processes have previously been termed selfpoisoning ${ }^{22}$. The result is that crystal growth is retarded or even stopped until the temperature is reduced sufficiently to permit the remaining shorter molecules to crystallise. Melting is the reverse of crystallisation and hence in Figure 3b, the less perfect crystals formed by the shorter molecules melt first, followed by the more perfect extended chain crystals. This argument is borne out by considering the melting point of the predominant population of extended chain crystals $\left(56.8^{\circ} \mathrm{C}\right)$ which is independent of thermal history as expected ${ }^{21}$ and is in good agreement with published data for the most abundant component $\mathrm{C}_{27} \mathrm{H}_{56}{ }^{23}$

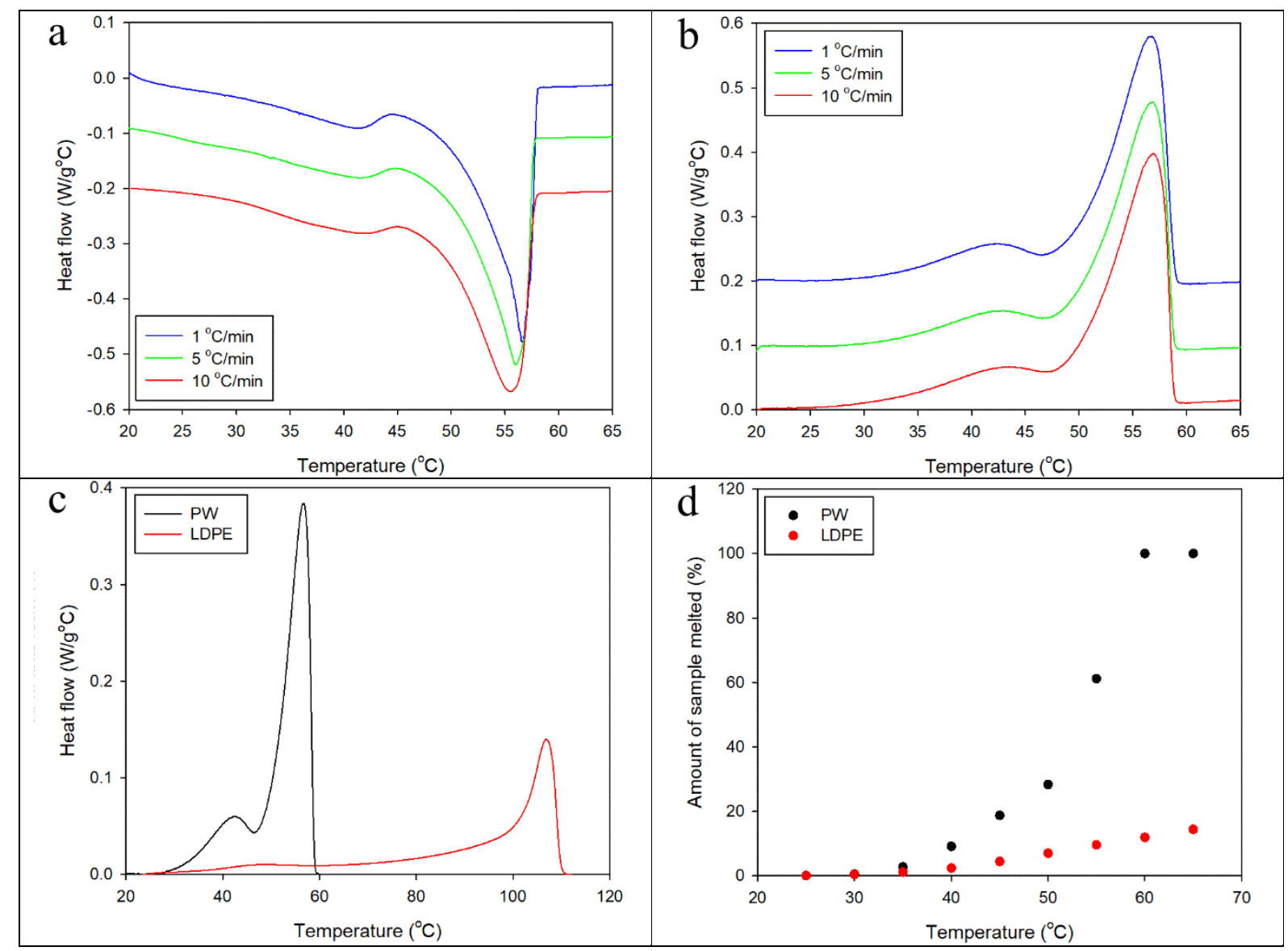


FIGURE 3. Results from DSC studies; (a) cooling curves of PW at the indicated rates, (b) subsequent melting behaviour, (c) comparison of melting behaviour of PW and LDPE (scan rate $1{ }^{\circ} \mathrm{C} / \mathrm{min}$ ), (d) an analysis of the proportion of sample melted as a function of temperature.

Melting scans of LDPE taken as supplied (Figure 3c) show a much higher peak melting temperature than the $\mathrm{PW}\left(\sim 107^{\circ} \mathrm{C}\right)$ and, again, its molecular composition (polydispersity, branch content and distribution) means it melts over a broad range of temperatures from 40 to $110^{\circ} \mathrm{C}$. The melting behaviour observed in the DSC is then a result of the lamellar population that forms as a consequence of the initially imposed crystallisation conditions and the extent to which these re-organise during the course of the DSC melting scan. This is exemplified in Figure 3d where, assuming a sufficiently slow scan rate to avoid instrumental thermal lag is used, the enthalpy up to temperature $T$ is a reflection of the proportion of the sample that has melted up to that point. LDPE shows some degree of partial melting at $65{ }^{\circ} \mathrm{C}$ whilst $\mathrm{PW}$ is completely melted at this temperature.

\section{Effects of water on C12}

C12 is an excellent material for exploring the effect of water on electrical conductivity, as its liquid nature over the temperature interval of interest allows its water content to be readily measured through conventional Karl Fischer titration. Initially, a number of conditioning experiments were carried out in order to ascertain how to prepare C12 samples with a range of defined water contents.

The as-supplied, anhydrous C12 was found to have a water content of 15 PPM and in order to reduce this, vacuum drying was used (P 0.5 mbar). A small quantity of broken cover slip was included in the test cell to permit the efficient nucleation of water bubbles and hence minimise any loss of C12 during drying. Figure 4a shows the effect of pumping time on water content (with an exponential fitted curve) and Figure 4b indicates its effect on the electrical conductivity measured at $25{ }^{\circ} \mathrm{C}$. Despite the obvious scatter in the conductivity data, both the water content and conductivity decrease with increasing drying time. After $2 \mathrm{~h}$ of conditioning, many water tests yielded null results and subsequent measurements of conductivity yielded values around the sensitivity limit of the equipment $\left(\sigma \sim 3 \times 10^{-17} \mathrm{~S} / \mathrm{cm}\right.$, dashed line in Figure 4b); this was therefore taken as a reasonable end point. To increase the water content, nominally anhydrous $\mathrm{C} 12$ was conditioned in ambient air $(\mathrm{RH}=50 \pm 20 \%)$ and, after a week of exposure, the water content was found to be $22 \pm 3$ PPM and after two weeks was hardly changed at $24 \pm 3$ PPM. Consequently at this point, conditioning was deemed to be complete. These numbers are consistent with the measured values of water solubility in n-alkanes. ${ }^{24}$
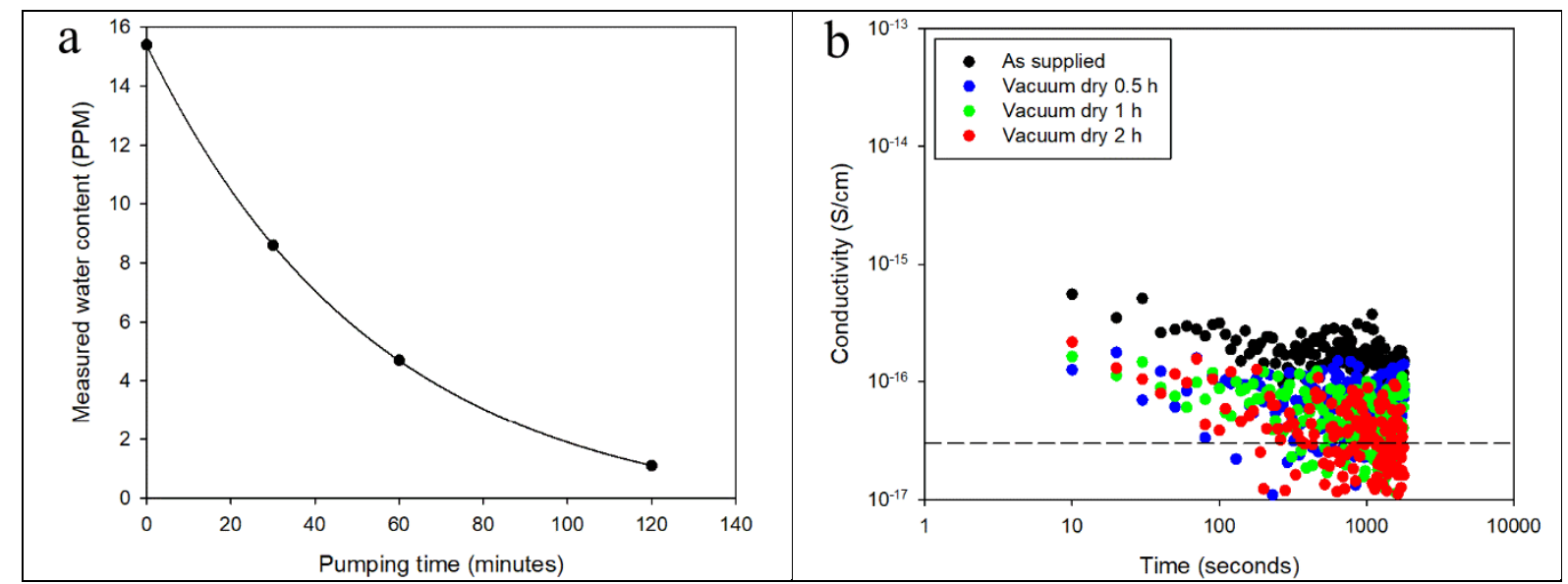

FIGURE 4. Effect of vacuum treatment on C12; (a) water content, (b) conductivity. 
Using the above information, a total of six samples was then prepared with varying initial water contents (Table 2) and the electrical conductivity of these was determined from $25{ }^{\circ} \mathrm{C}$ to $65{ }^{\circ} \mathrm{C}$. After the electrical measurements were completed, another set of water content measurements were made and it was observed that this final water content (Table 2) closely reflected the atmosphere in which the testing was performed (i.e. dry nitrogen $\sim 1 \mathrm{PPM}$, nitrogen 15 PPM, air 20 PPM).

TABLE 2. Details of C12-x samples used in these investigations (typical uncertainty \pm 3 PPM)

\begin{tabular}{|l|l|l|l|l|}
\hline Sample & Conditioning & Atmosphere & $\begin{array}{l}\text { Initial water } \\
\text { content } \\
\text { (PPM) }\end{array}$ & $\begin{array}{l}\text { Final water } \\
\text { content } \\
\text { (PPM) }\end{array}$ \\
\hline C12-1 & Vacuum dry (2 h) & Nitrogen + desiccant & 0 & 1 \\
\hline C12-2 & Vacuum dry (2 h) & Nitrogen & 1 & 13 \\
\hline C12-3 & Vacuum dry (1 h) & Nitrogen & 4 & 17 \\
\hline C12-4 & Vacuum dry (0.5 h) & Nitrogen & 8 & 12 \\
\hline C12-5 & As supplied & Nitrogen & 15 & 16 \\
\hline C12-6 & Air (50 \% RH, 2 weeks) & Air & 24 & 20 \\
\hline
\end{tabular}

Figures 5 a to $5 \mathrm{c}$ show examples of as-measured data from the conductivity experiments and the conductivity was found to decrease with time and increase with temperature. Initially, a high displacement current flows as polarisation charges are built-up adjacent to the electrodes, these then serve to limit further charge injection and hence the measured current in the external circuit falls. An equilibrium is eventually reached between injected charge and recombination of charge carriers in the bulk and the measured current then reflects the true conduction current. ${ }^{15,16}$ The short term fluctuations in some of the traces are due to variations in oven temperature (typical accuracy $\pm 2{ }^{\circ} \mathrm{C}$ ). Despite this, it is evident that the conductivity tends towards a steady state value for times, $t>2000 \mathrm{~s}$ at the lowest temperatures, and that this point is more quickly reached at higher temperatures. To determine the steady state conductivity $\sigma_{\text {inf }}$ (where $\sigma_{\text {inf }}=\sigma(t)$ at time $t=\infty$ ) a modified form of the Curie-Von Schweidler law (to take into account the finite conductivity at large $t$ ) ${ }^{25}$ was fitted to the data:

$$
\sigma(t)=\sigma_{\text {inf }}+a t^{-b}
$$

where $a$ and $b$ are positive constants. Using the values of $\sigma_{\text {inf, which more accurately reflect }}$ the true conductivity of the samples, the dependence of conductivity on both temperature and absorbed water is elucidated in Figure $5 d$ (uncertainty in these data typically $\pm 10 \%$ ). Clearly an increase in the absorbed water (Table 2) has a significant effect on the measured conductivity at $25{ }^{\circ} \mathrm{C}$, but an insignificant effect at $65{ }^{\circ} \mathrm{C}$. The role of water and temperature on electrical conductivity will be discussed in more detail in the next sections. 


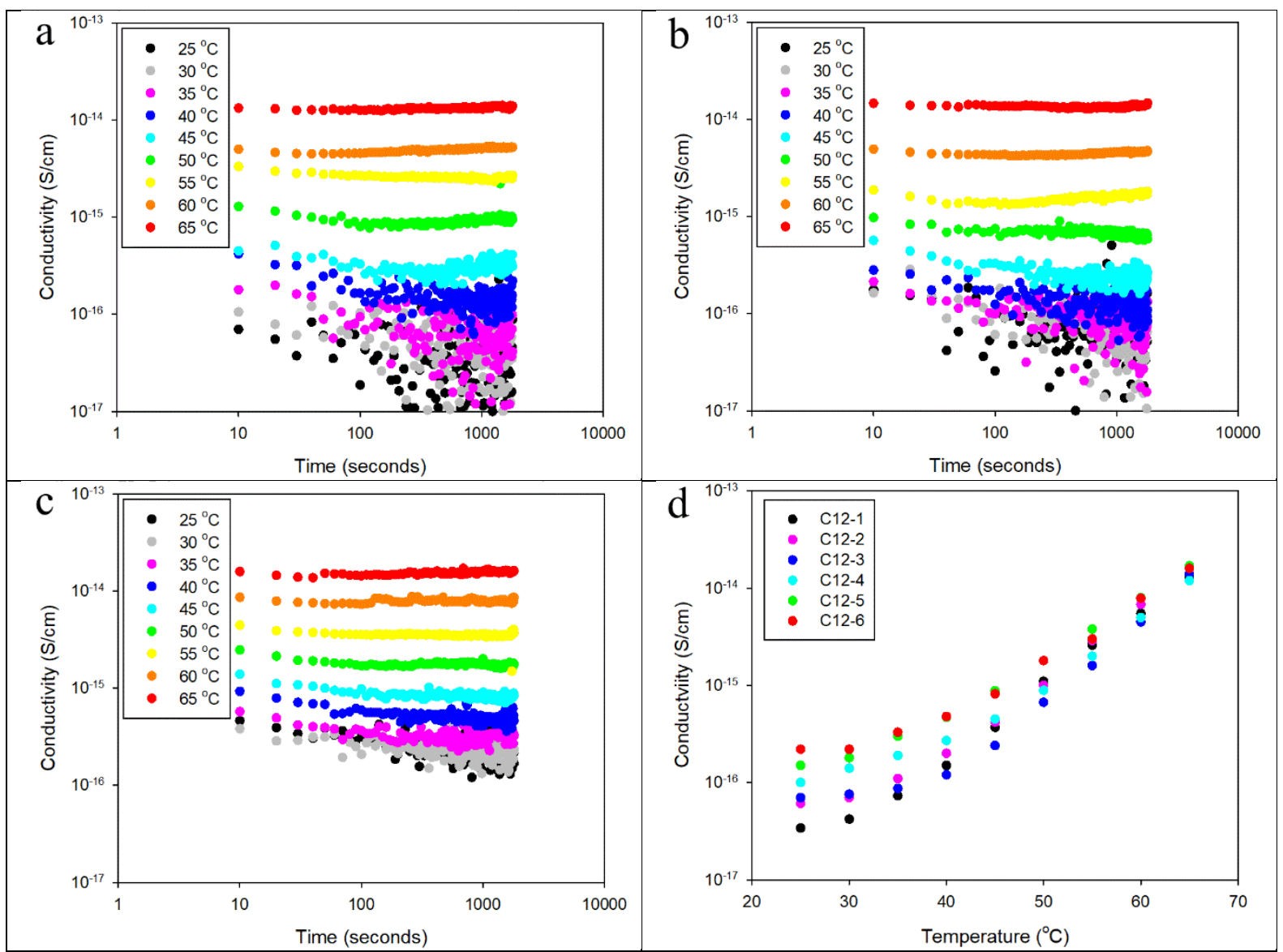

FIGURE 5. Conductivity behaviour of C12-x; (a) C12-1, (b) C12-3, (c) C12-6, (d) summary plot (values obtained through curve fitting).

\section{Comparison with theoretical models}

We model the effect of water by considering the number of extra charge carriers produced in C12 by the auto-ionisation of pure water, estimating the contribution of free excess electrons by using the conductivity of the C12-1 as our dry reference sample. The concentrations of absorbed water are high enough to contribute significant numbers of water ions with around a billion of each $\left(\mathrm{H}_{3} \mathrm{O}^{+}, \mathrm{OH}^{-}\right)$in our $1.05 \mathrm{~cm}^{3}$ sample at 20 PPM (1 PPM being $1 \mathrm{mg}$ of water per $1000 \mathrm{~cm}^{3}$ of sample) but not high enough to form a nanoscale film that might percolate (at 20 PPM, on average, there would be 1 water molecule per cube of side $11 \mathrm{~nm}$, while at 90 PPM one water molecule would be found in a cube of side $7 \mathrm{~nm}$ ). We assume in the following arguments that all water ions are separated by the electric field and driven to their respective electrodes, leading to an increase in conductivity. Furthermore, we assume that the tiny amount of water lost is continuously replenished from the atmosphere. At $25^{\circ} \mathrm{C}$ the ionisation constant of water ${ }^{26}$ is:

$$
K_{w}=\left[\mathrm{H}_{3} \mathrm{O}^{+}\right]\left[\mathrm{OH}^{-}\right]=10^{-14} \mathrm{~mol}^{2} \mathrm{dm}^{-6}
$$

this increases with temperature so that at $60{ }^{\circ} \mathrm{C}$ it is $9.3 \times 10^{-14} \mathrm{~mol}^{2} \mathrm{dm}^{-6}$, whilst extrapolation gives $10.5 \times 10^{-14} \mathrm{~mol}^{2} \mathrm{dm}^{-6}$ at $65^{\circ} \mathrm{C}$. Assuming that the speed of the ions:

$$
v=\mu E
$$


where $\mu$ is their mobility and $E$ the electric field, is sufficiently high to allow the transport of ions across the sample, this requires $\mu \geq 5 \times 10^{-6} \mathrm{~cm}^{2} \mathrm{~V}^{-1} \mathrm{~s}^{-1}$, which is much smaller than ionic mobility values in polymeric materials reported in the literature ${ }^{27}$ including the simulated value of $4.9 \times 10^{-4} \mathrm{~cm}^{2} \mathrm{~V}^{-1} \mathrm{~s}^{-1}$ for $\mathrm{OH}$ - ions in $\mathrm{PE}{ }^{28}$. We further assume that the water content of the sample is constant, as the number of dissociated water molecules reaching the electrodes is a tiny fraction of the total water content (if there are electrolytes present the conductivity can be higher). Finally, we assume that as we remove ions at the electrodes, further self-ionisation takes place to replace those ions lost through recombination at the electrodes; a water molecule will typically dissociate once every $10 \mathrm{~h}$ which, in our system, is fast enough to replenish all

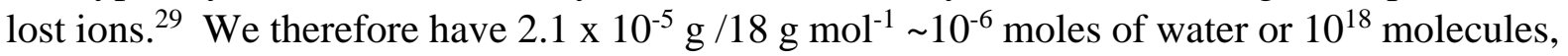
which produce a current, $I$, of $10^{13}$ ions of each species per second ( $10 \mathrm{~h}=36,000 \mathrm{~s}$ ), the vast majority of which recombine. Given a field $E=2 \mathrm{kV} / \mathrm{mm}$ and an electrode area $A$ of $10.5 \mathrm{~cm}^{2}$, the maximum water driven conductivity $\sigma_{w}$ can be determined for our sample using:

$$
\sigma_{w}=I / A E
$$

hence $\sigma_{w} \sim 5 \times 10^{-10} P \sqrt{ } K_{w}(T)$ S/cm where $P$ is the water concentration in PPM. Including the contribution of excess electrons by adding the conductivity of the dry sample, $\sigma_{0}(T)$, we obtain the total conductivity;

$$
\sigma(T)=\sigma 0(T)+5 \times 10^{-10} \alpha P \sqrt{ } K_{w}(T) \mathrm{S} / \mathrm{cm}
$$

where we allow charge recombination and trapping to reduce the number of water ions available from the maximum value by a fraction $\alpha$. We find that a value of $\alpha \sim 0.2$ gives a good fit of the model to the experimental data obtained at $25{ }^{\circ} \mathrm{C}$ and $65{ }^{\circ} \mathrm{C}$; temperatures where the water contents are known accurately (Figures 6a and 6b). Clearly, the predicted contribution of water ions to the total conductivity (solid lines) is very significant at $25{ }^{\circ} \mathrm{C}$ and insignificant at $65{ }^{\circ} \mathrm{C}$ reproducing the experimental findings (points with error bars added). The physical constants relevant to this section and the next are summarised in table 3.

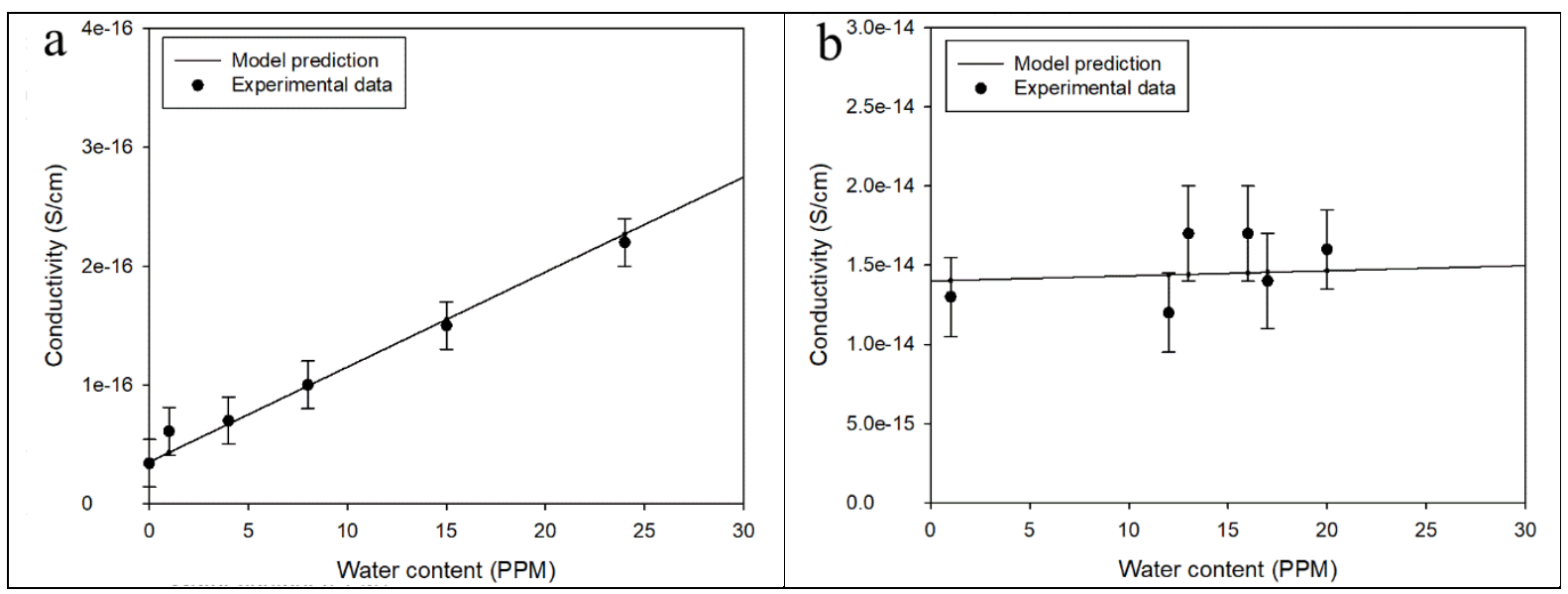

FIGURE 6. Comparison of model predictions (solid line) to experimental data at, (a) $25^{\circ} \mathrm{C}$, (b) $60{ }^{\circ} \mathrm{C}$.

TABLE 3: Physical constants for the conductivity calculations 


\begin{tabular}{|l|l|l|l|l|l|}
\hline $\begin{array}{l}\text { Ionisation } \\
\text { constant of } \\
\text { water }\end{array}$ & $\begin{array}{l}\text { Applied } \\
\text { field }\end{array}$ & $\begin{array}{l}\text { Conductivity } \\
\text { due to water } \\
\text { at } P \text { PPM }\end{array}$ & $\begin{array}{l}\text { Recombination } \\
\text { coefficient }\end{array}$ & $\begin{array}{l}r_{\sigma}=\sigma\left(60^{\circ} \mathrm{C}\right) / \sigma \\
\left(30^{\circ} \mathrm{C}\right)\end{array}$ & $\begin{array}{l}r_{\sigma}=\sigma\left(60^{\circ} \mathrm{C}\right) / \sigma \\
\left(30^{\circ} \mathrm{C}\right)\end{array}$ \\
\hline$K_{w}\left(25^{\circ} \mathrm{C}\right)$ & $\mathrm{E}$ & $\sigma_{w}$ & $\alpha$ & $L D P E$ & $C 12-1$ \\
\hline $\begin{array}{l}10^{-14} \\
\mathrm{~mol}^{2} \mathrm{dm}^{-6}\end{array}$ & $2 \mathrm{kV} / \mathrm{mm}$ & $\begin{array}{l}5 \times 10^{-10} \\
\alpha P \sqrt{ } K_{w}(T) \\
\mathrm{S} / \mathrm{cm}\end{array}$ & 0.2 & 5 & 150 \\
\hline
\end{tabular}

\section{Preliminary comparison of C12-x, PW and LDPE}

For this preliminary comparison and for equivalence with the conditioning imposed on C12-5, LDPE and PW were both used as supplied. Example data are shown from PW in Figure 7a and as observed above, the conductivity of both PW and LDPE tend towards a stable value after $\sim 2000$ s with some short term fluctuations evident due to variations in oven temperature. Accordingly, the same power law fitting procedure (see eq. 1) was used to estimate the steady state conductivity $\left(\sigma_{\text {inf }}\right)$. As a validation of this technique, the average of the last twenty data points was taken to provide a second, more direct, estimation of conductivity; we term this parameter $\sigma_{\text {avg. }}$. The values obtained from the two analysis techniques from all the experimental data are compared in Figure $7 \mathrm{~b}$. The fitted line has a gradient of $0.94 \pm 0.01$, indicating that taking the average of the last 20 data points overestimates the conductivity by around $6 \%$. Power law fitting clearly provides a more accurate estimation of the final steady state conductivity, as anticipated.

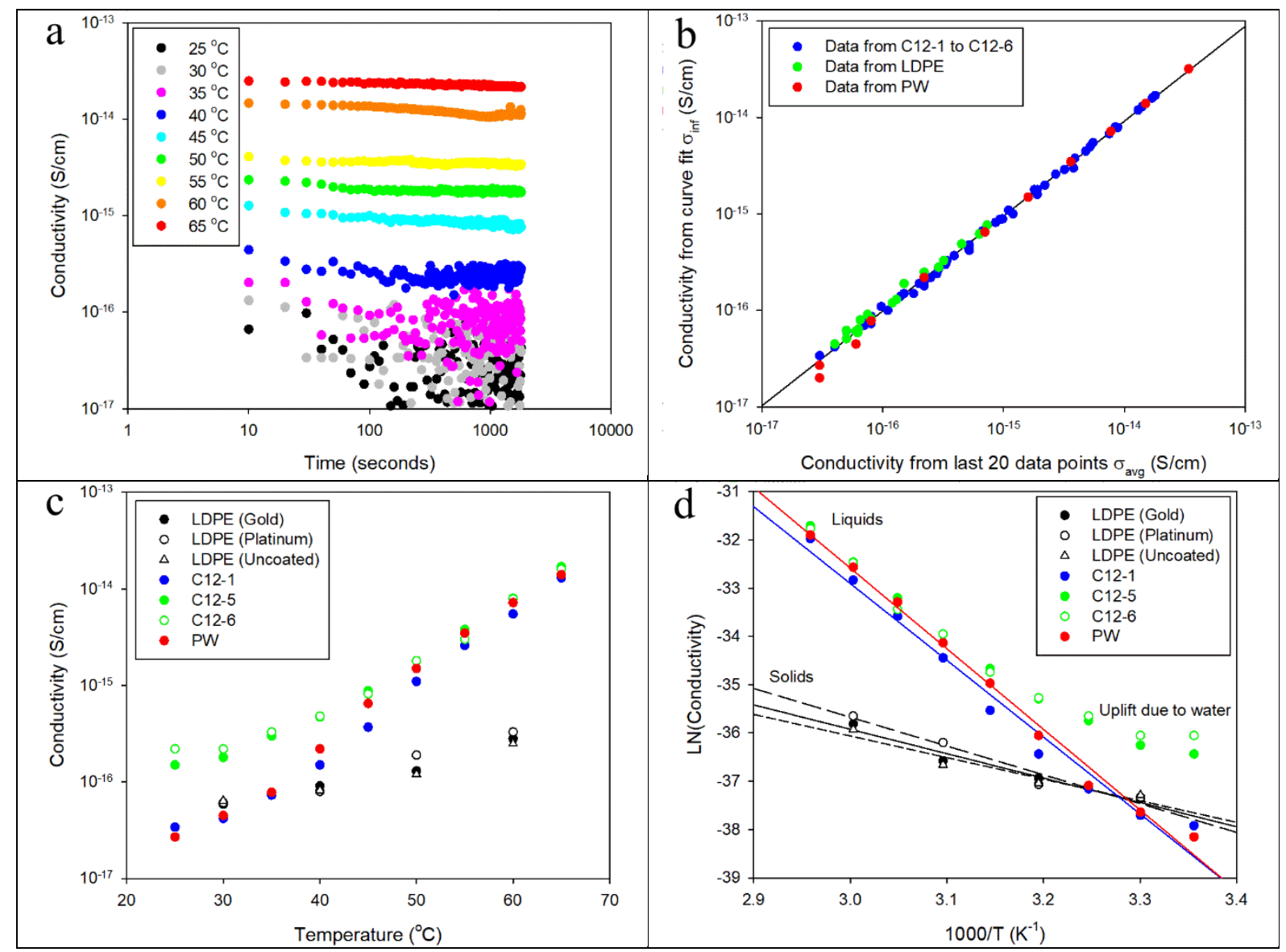

FIGURE 7. Conductivity data; (a) as collected data from PW, (b) validation of power law fitting, (c) comparison of LDPE, C12-x and PW, (d) Arrhenius plot. 
Considering, now, Figure 7c and the Arrhenius plot shown in Figure 7d, it is evident that the values obtained for LDPE are consistent with the available literature. ${ }^{15}$ We have taken steps to minimise the effects of the electrodes on the measured data by using a low enough applied field ${ }^{7,14}$ and, as a result, we observe that the conductivity of the LDPE is independent of the electrode material.

The current density $J$ at temperature $T$, in the absence of diffusion and polarization currents, can be written as;

$$
J=\rho(T) e \mu(T) E
$$

where $\rho$ is the mean electron density, $e$ the charge on the electron, $\mu$ the electron mobility and $E$ the applied field giving the conductivity as $\sigma=J / E=\rho(T) e \mu(T)$. The electron mobility can be calculated from the Kubo - Greenwood formula ${ }^{30,31}$; however, for electron trap energies, $E_{t}$, significantly greater than the thermal energy $\mathrm{k} T,{ }^{5}$ this approximates to;

$$
\mu(T)=\mu \mathrm{e}^{-\beta E t}
$$

For amorphous polyethylene we have molecular simulation data for the activation energy $E_{t}=-0.27 \mathrm{eV}$ and, hence, we can predict the electron mobility (Table II in ref. no. 5), and hence the conductivity, assuming transport is dominated by physical traps only and that $\rho$ is constant here fitted to LDPE conductivity at $30{ }^{\circ} \mathrm{C}$. Using this approach, in which the temperature variation in conductivity is due entirely to the change in mobility, the ratio $r_{\sigma}$, of the predicted conductivity at $60{ }^{\circ} \mathrm{C}$ to that at $30{ }^{\circ} \mathrm{C}$ is 3 . This should be compared to the data obtained from the LDPE specimens, which is characterised by $r_{\sigma}=\left(3 \times 10^{-16}\right) /\left(6 \times 10^{-17}\right)=5$. This discrepancy may be due to partial melting of the LDPE; for example, at $60{ }^{\circ} \mathrm{C}$ we observe that roughly 12 $\%$ of the sample is melted (see Figure 3d), although it is also within the experimental error of the measured data. Note an Arrhenius plot of the LDPE data (Table 4, Figure 7d) gives a somewhat higher activation energy of $\sim 0.4 \mathrm{eV}$, the difference presumably arising from partial melting and/or the experimental uncertainty.

C12 is in a liquid state and in the absence of water (C12-1), its $r_{\sigma}$ value is given by $6 \times 10^{-15} / 4 \times 10^{-17}=150$. From the measured data ${ }^{32}$ for the mobility of an excess electron in the liquid range of $\mathrm{C} 12$ we find that the mobility increases by a factor of two between $30{ }^{\circ} \mathrm{C}$ and $60{ }^{\circ} \mathrm{C}$. This is also consistent with the measured change in viscosity over the same range; using a Stokes-Einstein relation for the change in diffusion coefficient with viscosity also gives a factor of two increase in conductivity, ${ }^{33}$ which implies from the Kubo - Greenwood formula (eq. 7) that $E_{t}=-0.17 \mathrm{eV}$, very similar to the $-0.27 \mathrm{eV}$ trap energy of LDPE. Thus, the large increase in the measured conductivity cannot be due to the temperature dependence of the mobility. We note that the Arrhenius activation energy ( $E_{a}$, Table 4 ) is $\sim 1.3 \mathrm{eV}$; which is significantly higher than that of LDPE and any trap energy consistent with the measured temperature dependence of the mobility. Rather similar activation energies were obtained from C12-5 and C12-6 (Table 4) considering only data for $\mathrm{T} \geq 40{ }^{\circ} \mathrm{C}$ (where the effects of water are minimal) and for PW $(\sim 1.4 \mathrm{eV})$. These data imply that there must be a second thermally activated process occurring, which drives the large change in conductivity with temperature. Looking at our formula for the conductivity, $\sigma(T)=\rho(T) e \mu(T)$, the experimental conductivity data imply an exponential increase in the number density of excess electrons in liquid C12 with increasing temperature and an activation energy of $\sim 1.37-0.17=1.2 \mathrm{eV}$. Similar arguments hold for PW. We also note that the temperature driven change of electrical conductivity in C12 is much greater than that found elsewhere, for example, in lubricating oils. ${ }^{18}$

Finally, considering PW, for $T \leq 35^{\circ} \mathrm{C}$, its conductivity is not markedly different from that of LDPE and C12-1. We know that the water content of C12-1 is 1 PPM and, accordingly, 
we can surmise that the water content of both PW and LDPE, which closely follow the behaviour of the C12-1, are also negligible. At $40{ }^{\circ} \mathrm{C}$, PW starts to melt (Figures 3c and 3d) and the conductivity mimics that of $\mathrm{C} 12-1$ as the temperature increases. Our water model calculations (eq. 5) indicate that variations in water content have little or no influence for $T \geq$ $50{ }^{\circ} \mathrm{C}$ and, accordingly, in this regime, all three of the C12 samples and PW share a common behaviour. For $\mathrm{T} \geq 60{ }^{\circ} \mathrm{C}$ the crucial difference between these four systems and LDPE is that they are all liquids, whereas the LDPE is only partially melted (Figure 3d). This implies that the presence of a lamellar microstructure plays a major role in inhibiting electrical conductivity. However, we can also speculate that this behaviour could be due to a less efficient contact of the LDPE at the electrodes compared to the waxes in the melt phase. Certainly the rapid increase of the conductivity with temperature above $40{ }^{\circ} \mathrm{C}$, which we speculate is due to an exponential increase in electron density, occurs only once the materials have melted.

TABLE 4: Activation energies from Arrhenius plot (see Figure 7d)

\begin{tabular}{|l|l|l|l|}
\hline Sample & $\boldsymbol{E}_{\boldsymbol{a}}(\mathbf{e V})$ & $\left.\boldsymbol{E}_{\boldsymbol{a}} \mathbf{( k J} / \mathbf{m o l}\right)$ & Comments \\
\hline LDPE (Gold) & $0.44 \pm 0.06$ & $42 \pm 6$ & \\
\hline LDPE (Platinum) & $0.51 \pm 0.07$ & $50 \pm 7$ & \\
\hline LDPE (Uncoated) & $0.39 \pm 0.07$ & $37 \pm 7$ & \\
\hline C12-1 & $1.37 \pm 0.08$ & $132 \pm 8$ & \\
\hline C12-5 & $1.32 \pm 0.02$ & $127 \pm 2$ & Excluding T $\leq 40{ }^{\circ} \mathrm{C}$ \\
\hline C12-6 & $1.29 \pm 0.07$ & $124 \pm 6$ & Excluding T $\leq 40^{\circ} \mathrm{C}$ \\
\hline PW & $1.44 \pm 0.05$ & $139 \pm 5$ & \\
\hline
\end{tabular}

\section{CONCLUSIONS}

The electrical conductivity of ultra-pure dodecane $\left(\mathrm{C}_{12} \mathrm{H}_{26}\right)$ (impurity content $<200 \mathrm{PPM}$ ) was measured as a function of water content and compared to a model of charge transport which includes contributions from the self-ionisation of water. Good agreement was found between theory and experiment, demonstrating that the presence of free water ions constitutes a major factor in the observed variations in conductivity with water content, particularly at temperatures $\leq 50{ }^{\circ} \mathrm{C}$. Controlling water content will allow for more accurate measurements of the underlying conductivity of new and existing dielectric materials, facilitating progress in the development of new materials displaying lower losses and higher voltage tolerances.

The conductivity behaviour of n-dodecane, a paraffin wax and low-density polyethylene were then compared. It was found that LDPE showed a small dependence of conductivity on temperature, consistent with the electron trap energy of $\sim 0.3 \mathrm{eV}$ deduced from atomistic simulations. In contrast, water free n-dodecane (C12-1) and the paraffin wax reproducibly exhibited a much stronger dependence on temperature, with an Arrhenius activation energy in the range of $1.3-1.4 \mathrm{eV}$, which does not arise from the temperature dependence of the mobility. Our data suggest that in these molten materials, there is an exponential increase in the excess electron density with temperature not found in LDPE nor in lubricating oils: the origin of this increase is currently unknown and further work is therefore, needed to reveal its origins.

The similarity of the conductivity behaviour of water free n-dodecane and the paraffin wax suggests that the latter has negligible water content. LDPE at the same temperature as the liquid wax, exhibited a much lower conductivity implying that a semi-crystalline morphology may impede charge transport. A detailed treatment of the effects of morphology and sample conditioning will be provided in a future publication. 


\section{ACKNOWLEDGEMENTS}

The authors would like to thank the Engineering and Physical Science Research Council EPSRC for supporting this work through the Advanced Polymer Materials for Energy Security - POLYMAT grant, EP/N002288/1. We would like to thank Julie Herniman for carrying out the GC-MS work. Data published in this paper are available from the University of Southampton repository: https://doi.org/10.5258/SOTON/D1125

\section{REFERENCES}

1. Dissado, L. A.; Fothergill, J. C. In Electrical Degradation and Breakdown in Polymers; Ed. Stevens, G. C., Ed.; Peter Peregrinus Ltd, London, 1992.

2. According to the International Electrotechnical Commission: http://www.iec.ch/ (accessed May 22, 2019).

3. Saiz, F.; Cubero, D.; Quirke N. Phys. Chem. Chem. Phys., 2018, 20, 25186-25194.

4. Liu, Z.; Berne, B. J. J. Chem. Phys., 1993, 99, 9054-9069.

5. Wang, Y.; MacKernan, D.; Cubero, D.; Coker D. F.; Quirke N. J. Chem. Phys., 2014, 140, Art. No. 154902.

6. Meunier, M.; Quirke, N.; Aslanides, A. J. Chem. Phys., 2001, 115, 2876-2881.

7. Anta, J. A.; Marcelli, G.; Meunier, M., Quirke, N. J. Appl. Phys., 2002, 92, 1002-1008.

8. Saiz, F.; Quirke N. Phys. Chem. Chem. Phys., 2018, 20, 27528-27538.

9. Virtanen, S.; Vaughan A. S.; Yang, S.; Saiz, F.; Quirke, N. In Proc. 25th Nord. Insul. Symp., DOI: https://doi.org/10.5324/nordis.v0i25.2368, 2017. Västerås, Sweden, 19-21 June 2017.

10. Gemant, A. Z. Phys., 1932, 75, 613.

11. Jackson, W. Nature, 1934, 133, 647.

12. Gemant, A. Nature, 1935, 135, 912.

13. Vahidi, F.; Haegele, S.; Tenbohlen, S.; Rapp, K.; Sbravati, A. In Proc. 2017 IEEE Electr. Insul. Conf., 2017, 290-293. Baltimore, MA, USA, 11-14 June 2017.

14. Virtanen, S.; Vaughan, A. S.; Yang, L.; Saiz, F.; Quirke, N. In Proc. 2016 IEEE Conf. Electr. Insul. Diel. Phen., 2016, 58-61. Toronto, Canada, 17-20 October 2016.

15. Upadhyay, A. K.; Reddy, C. C. J. Appl. Phys., 2017, 122, Art. No. 064105.

16. Lau, K. Y.; Vaughan, A. S.; Chen, G.; Hosier, I. L.; Ching, K. Y.; Quirke N. J. Phys. D: Appl. Phys., 2016, 49, Art. No. 295305.

17. Park, J. K.; Ryu, J. C.; Kim, W. K.; Kang, K. H. J. Phys. Chem. B, 2009, 113, 12271-12276.

18. Abedian, B, Baker, K. N. IEEE Trans. Diel. Electr. Insul., 2008, 15, 888-892.

19. Tebani M.; Boudou, L.; Guastavino, J. J. Appl. Polym. Sci., 2008, 109, 2768-2773.

20. Liu, S.; Veysey, S. W.; Fifield, L. S.; Bowler, N. Polym. Degr. Stab., 2018, 156, 252-258.

21. Mandlekern, L.; Prasad, A.; Alamo, R. G.; Stack, G. M. Macromol., 1990, 23, 3696-3700.

22. Abo el Maaty, M. I. Polym. J. 1999, 31, 778-783.

23. Broadhurst, M. G. J. Res. Nat. Bur. Stand., 1962, 66A, 241-249.

24. Polak, J.; Lu, B. Can. J. Chem., 1973, 51, 4018-4023.

25. Guo, T. C.; Guo, W. W. J. Phys. C - Sol. St. Phys., 1983, 16, 1955-1960.

26. Covington, A. K.; Ferra, M. I. A.; Robinson, R. A. J. Chem. Soc., Far. Trans., 1977, I 73, 1721-1730.

27. Fragiadakis, D.; Dou, S.; Colby R. H.; Runt, J. Macromol., 2008, 41, 5723-5728.

28. Huang. Y.; Jämbeck. J.; Unge. M. ACS Macro Lett., 2017, 6, 571-574.

29. Eigen, M.; De Maeyer L. Ber. der Bunseng. für Physic. Chem., 1955, 59, 986-993.

30. Kubo, R. J. Phys. Soc. Jap., 1957, 12, 570-586.

31. Greenwood, D. A. Proc. Phys. Soc., 1958, 71, 585-596. 
32. N. Gee, G. R. Freeman, J. Chem. Phys., 1987, 86, 5716-572.

33. Caudwell, D. R.; Trusler, J. P. M.; Vesovic, V.; Wakeham M. A. Intern. J. Thermophys., 2004, 25, 1339-1352. 